\title{
Optimization of olive-fruit paste production using a methodological proposal based on a sensory and objective color analysis
}

\author{
By María Luisa Escudero-Gilete, A.J. Meléndez-Martínez, F.J. Heredia and Isabel M. Vicario*
}

\author{
Department of Food Science and Nutrition. Faculty of Pharmacy. \\ University of Seville. P. García González, 2. 41012 Sevilla. Spain
}

( ${ }^{\star}$ Corresponding author: vicario@us.es)

\section{RESUMEN}

Optimización de la producción de una pasta de aceituna utilizando una propuesta metodológica basada en el análisis sensorial y la medida objetiva del color.

Este trabajo presenta la optimización de las condiciones de formulación de una pasta de aceitunas. La elaboración comprendió diferentes fases: lavado, mezcla, adición de aceite y conservación. Un panel entrenado y un panel de consumidores realizaron pruebas de comparación por pareja y test de ordenación para seleccionar la muestra preferida en cada fase. Los atributos sensoriales considerados fueron sabor, textura visual, textura en boca y preferencia total. Los resultados del análisis sensorial se procesaron estadísticamente mediante ANOVA y el test de Friedman para seleccionar las condiciones óptimas de elaboración: lavado 3 veces durante 30 minutos, mezclado a 2000 r.p.m y adición de 10 $\mathrm{mL}$ de aceite de cobertura. Se ensayaron diferentes condiciones de pasteurización $\left(62.5,75,85\right.$ y $95{ }^{\circ} \mathrm{C}$ durante 15 minutes). No se encontraron diferencias significativas $(p<0.05)$ de color $(C I E L A B)$ entre las pastas sometidas a diferentes condiciones de conservación. En base a los resultados del test de preferencia, las condiciones seleccionadas fueron: calentar a $85{ }^{\circ} \mathrm{C}$ durante 15 minutos.

PALABRAS CLAVE: Análisis sensorial - Desarrollo de producto - Producción de paté de aceitunas - Test de comparación por parejas - Test de ordenación.

\section{SUMMARY}

Optimization of olive-fruit paste production using a methodological proposal based on a sensory and objective color analysis.

This paper deals with the optimization of the conditions to formulate paste based on olive fruits. The processing stages included: washing, blending, oil addition and preservation. Pair-comparisons and ranking tests were carried out by both a trained panel and a consumer panel to single out the preferred sample at each stage. The sensory attributes considered were taste, visual texture, texture in the mouth and overall preference. The results of the sensory analyses were processed statistically by means of ANOVA and the Friedman test to select the most appropriate processing conditions: washing for 30 minutes three times, blending at 2000 r.p.m, and the addition of $10 \mathrm{~mL}$ of oil. Several pasteurization conditions were assayed (62.5, 75, 85 and $95{ }^{\circ} \mathrm{C}$ for 15 minutes). No significant color differences $(p<0.05)$ were found for the objective color measurement (CIELAB) of the pastes submitted to the different pasteurization conditions. Based on the results of the preference test, the pasteurization conditions selected were heating at $85^{\circ} \mathrm{C}$ for 15 minutes.

KEY-WORDS: Olive paste production - Pair-comparison test - Product development - Rank order test - Sensory analysis.

\section{INTRODUCTION}

The food industry is a dynamic system that needs to innovate itself almost constantly in order to meet consumers' demands. During the development and marketing of a new foodstuff it is important to consider many aspects related to its quality from different angles (psychological, technological, legal, etc.). Concerning legal matters, it is crucial to consider food safety as well its nutritional, sensory and commercial quality, among other aspects (Moskowitz et al., 2005). Nonetheless, there are also other factors like flavor, texture, and appearance which play a prominent role in the acceptability of foods and must be therefore assessed (Coleman, 1990; Lawless and Michelle, 1993; Pecore and Kellen, 2002; González et al, 2007). In this regard, it is indisputable that the consumer's opinion is critical (Moldão-Martins et al., 2004; Muñoz et al., 1992; Yantis, 1992). Consequently, modern food companies pay great attention to the evaluation of the sensory attributes of foodstuffs by both trained panels and potential consumers, which is essential in the development, maintenance, optimization, quality improvement and assessment of new products (Coello et al., 1999; Abu-Salem and Abou-Arab, 2008). For example, appropriate preference tests have been performed to optimize a reduced-calorie tropical mixed-fruit jam (Abdullah and Cheng, 2001), the texture of spaghettis enriched with resistant starch (Sozer et al., 2007), a chocolate-flavored peanut-soy beverage (Deshpande et al., 2008) or the formulation of an apple pomace and a quince jelly (Royer et al., 2006), among others.

Olive fruit is a typical product from the Mediterranean basin. Its praised lipid content is characterized by the predominance of unsaturated fatty acids (mainly oleic acid) over the saturated ones, hence it is considered quite healthy. In addition, it is a good source of other compounds 
with nutritional importance like dietary fiber, vitamins, minerals and antioxidants. According to the IOOC (2004) "table olives are the sound fruit of varieties of the cultivated olive tree (Olea europaea L.) that are chosen for their production of olives, whose volume, shape, flesh-to-stone ratio, fine flesh taste, firmness and ease of detachment from the stone make them particularly suitable for processing; treated to remove its bitterness and preserved by natural fermentation; or by heat treatment, with or without the addition of preservatives; packed with or without covering liquid" (Sánchez Gómez et al., 2006). Due to the positive image of the olive fruits and their derived products, the demand for new products elaborated with them and olive oil has increased markedly over the past years.

According to the prevailing legislation, olive oil can be used as an ingredient in the elaboration of table olive products. In relation to their preservation, olive fruits fit for consumption can be subjected to different processes. One of them is pasteurization, which leads to the destruction of the vegetative forms of pathogenic and banal nature microorganisms. In the case of table olives, the microorganism of reference is the propionic bacteria (González, 1982). The effect of thermal treatments on the color and texture of pickled green olives has been assessed by Sánchez et al. (1991), who concluded that such organoleptic attributes did not change appreciably as a result of the pasteurization treatments necessary to guarantee the product's stability. This kind of analysis is important as it is indisputable that the color of foods, which depends on their composition and therefore can be affected by industrial practices, dramatically influences consumer preferences (Calvo et al., 2001; Hutchings, 1994). Furthermore, the color of a food is the first contact point of the consumers with it at the market and the first attribute considered in sensory analyses.

The objective of this study was to develop a new product fulfilling suitable levels of hygienic-sanitary and organoleptic quality at the request of a company that markets olive-based products. The experimental design was established after considering and evaluating statistically the results of the sensory analyses of different formulations. In summary, it can be claimed that this undertaking is a good example of collaboration between the industry and researchers in Food Science and Technology for the sensible a meaningful design of a new product.

\section{MATERIALS AND METHODS}

The raw materials used for the elaboration of pastes were of a standard quality to minimize season to season variations. Pitted table olives from the Manzanilla variety stored in highly salted brine were used due to its high pulp to stone relation and its acceptable oil content. The covering virgin olive oil was obtained from Hojiblanca olives.

\subsection{Paste formulation}

The flow diagram of the different stages leading to the formulation of the final product is shown in Figure 1. Two main stages can be distinguished:

- The first one included the procedures followed to obtain the final quantitative formulation (washing, blending, oil addition and final formula).

- The second one corresponded to the different preservation conditions tested.

The codes of the samples are numbered and explained in Table 1.

\section{Washing}

In order to obtain olives with a suitable salt content it was necessary to establish washing conditions (time and number of water changes). Four paste samples ([T00], [T30], [T60], [T90]) were elaborated (Table 1)

\section{Texture}

The pastes were prepared with washed pitted olives. The texture depended on the granularity of the olives. In some cases, virgin olive oil (always the same amount) was added during the blending. The blending was performed with either a 600 watt MMB2000 domestic blender (Bosch, GerlingenStuttgart, Germany) or an Abencor laboratory oil mill (Abengoa, Seville, Spain). Three different granularities were obtained: fine-grained $[F]$, medium-grained [M] and large-grained or coarse [L] (Table 1).

\section{Added oil/Covering oil}

The pastes with added oil were produced adding $50 \mathrm{~g}$ of virgin olive oil/ $\mathrm{kg}$ of olive fruits. The samples with covering oil contained $15 \mathrm{~mL}$ of virgin olive oil $/ 250 \mathrm{~g}$ of paste.

\section{Preservation conditions}

The four pasteurization methods tested (Table 1) were performed using a temperature controlled water bath (Selecta, Barcelona, Spain). For this purpose $100 \mathrm{~g}$ glass containers filled with paste and covered with olive oil were used. After the thermal treatments the containers were kept in a fridge at $4-8{ }^{\circ} \mathrm{C}$.

\subsection{Experimental design}

Three different variables were taken into account for the formulation of the paste: salty taste, texture and the addition or not of oil. Each variable comprised 3-4 levels. Once the most appropriate formulation was singled out, four different pasteurization temperatures were assayed, as well 


\section{PRODUCT FORMULATION}

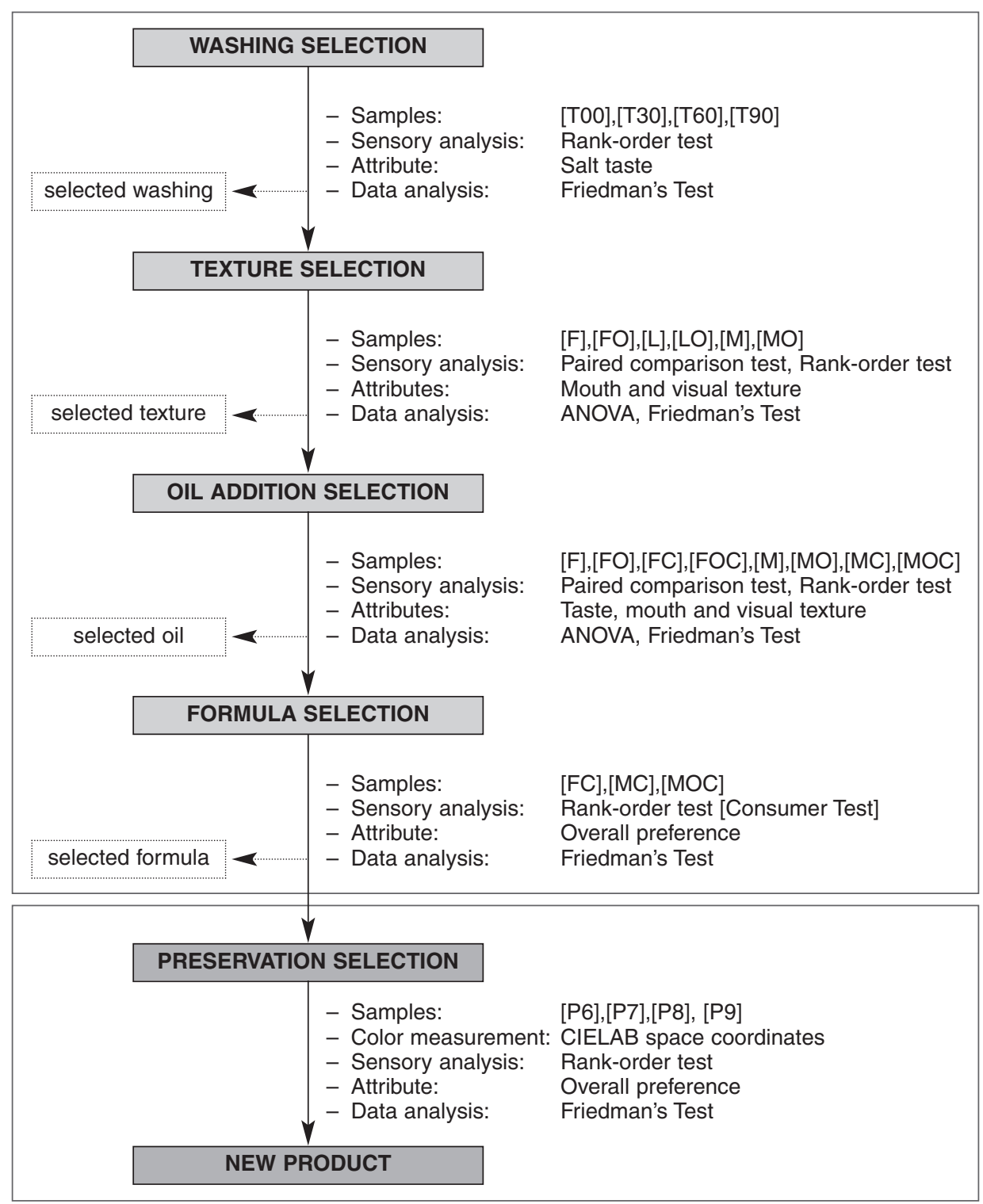

Figure 1

Flow diagram of the stages leading to the development of the new product.

as their impact on the sensory quality of the final product. In order to facilitate the selection process, an approach based on a phase by phase choice of attributes by sensory analysis was followed. Paired comparison tests (ISO 5495, 1983) and preference ranking tests (ISO 8587, 2001) were conducted at each stage in order to decide the formula that passed to the next optimization phase. The final experimental design is summarized in Table 1.

\section{Sensory analyses}

Either a trained or a consumer panel was used depending on the purpose of the analysis. A comprehensively trained 10 -judge panel took part in the tests in the initial formulation stages. The members of this panel were chosen from trained academics with long expertise in the sensory analysis of food for research and quality control purposes. In the final stage, the sensory analyses were performed by a consumer panel of 40 people randomly recruited at the university campus. This gender-balanced panel consisted of students and university staff lacking training in sensory analysis and with ages ranging between 25 and 55 . The judges were asked to rank the samples according to their overall preference considering the following attributes: appearance (mainly related to color), texture and both taste and aroma quality and intensity.

The assessments were carried out in individual booths $(70 \times 70 \times 55 \mathrm{~cm})$ at room temperature and under white light. Twenty-gram samples of paste at $25^{\circ} \mathrm{C}$ were presented in white plastic plates labeled 
Table 1

Description of samples codes

\begin{tabular}{|c|c|}
\hline CODE & DESCRIPTION \\
\hline [T00] & Drained and crushed olive \\
\hline [T30] & Olive washed and kept in water for 30 minutes (changing the water every 15 minutes), drained and crushed \\
\hline [T60] & Olive washed and kept in water for 60 minutes (changing the water every 30 minutes), drained and crushed \\
\hline [T90] & Olive washed and kept in water for 90 minutes (changing the water every 30 minutes), drained and crushed \\
\hline [L] & Large-grained: coarsely whipped with domestic blender \\
\hline [LO] & Large-grained with olive oil: [L] with olive oil \\
\hline [M] & Medium-grained: whipped with Abencor mill \\
\hline [MO] & Medium-grained with olive oil: [M] with olive oil \\
\hline [MC] & Medium-grained with covering: $[\mathrm{M}]$ with covering olive oil \\
\hline [MOC] & Medium-grained with olive oil and covering: [MO] with covering olive oil \\
\hline$[F]$ & Fine-grained: finely whipped with domestic blender \\
\hline [FO] & Fine-grained with olive oil: [F] with olive oil \\
\hline [FC] & Fine-grained with covering: $[\mathrm{F}]$ with covering olive oil \\
\hline [FOC] & Fine-grained with olive oil and covering: [FO] with covering olive oil \\
\hline [P6] & Pasteurization at $62.5^{\circ} \mathrm{C}$ during 15 minutes \\
\hline [P7] & Pasteurization at $75{ }^{\circ} \mathrm{C}$ during 15 minutes \\
\hline [P8] & Pasteurization at $85^{\circ} \mathrm{C}$ during 15 minutes \\
\hline [P9] & Pasteurization at $95^{\circ} \mathrm{C}$ during 15 minutes \\
\hline
\end{tabular}

with three-digit random codes. A glass of water was offered to the judges between samples to rinse their mouths. To prevent biases related to the serving order, this was determined by random permutation. Furthermore the codes were different for each test.

\section{Paired comparison test}

Paired comparison tests were used to determine preferences regarding texture and oil addition. They judge were asked to answer the following questions:

1. "Is there any difference between the samples?"

2. "What sample is more [attribute]?"

3. "What sample do you prefer in terms of [attribute]?"

When differences were noticed, one point was assigned to the favorite sample and 0 points to the other. When no differences between samples were detected, 0 points were assigned to both samples. All the points were summed up and divided by the number of judges to obtain the final score of each sample. When three samples had to be tested, three comparison tests were carried out and the maximum score of the sample was 2 . To test 4 samples, six comparison tests were carried out and the maximum score of the sample was 3 .

Concerning texture, the attributes considered were visual appearance and sensation in the mouth. In the case of the addition of oil the attributes considered were visual texture, sensation in the mouth and taste.

\section{Rank-order test}

This test allowed the differences among several samples to be estimated in terms of overall liking. The samples, in random order, were presented simultaneously to the judges, who were asked to taste and rank them according to their degree of preference once the different attributes tested had been considered. This test was applied in the different stages of the process (Figure 1).

\section{Statistical analysis}

The software Statistica $®$ v 6.0 (StatSoft, 2001) was used for the statistical treatment of the data. Analysis of variance (ANOVA) were carried out to ascertain whether there were significant differences $(p<0.05)$ between samples (Norman and Streiner, 1996). Additionally, significant post hoc analyses were performed (Tukey HSD test if variances in the different groups were identical or Games-Howell test if they were not). The homogeneity of variance was tested by Levene's Test.

Friedman's two-way analysis of variance was carried out when the variables were measured in terms of categories. As recommended by the ISO 8587, this test (Friedman, 1937) was considered to establish the statistical significance of the differences that the panelists might detect between samples. The differences among the Friedman's rank sums were compared to critical values calculated according to Hollander et al. (1973). When according to the Friedman's test statistically significant differences among samples were found, the pairs of differing samples were identified using an analogue of Fisher's least significant difference (Fisher, 1998).

\subsection{Objective color measurement}

The reflectance color measurements were made using a CAS 140 B spectroradiometer (Instrument Systems, Munich, Germany) fitted with a Top 100 telescope optical probe (Instrument Systems, Munich, Germany) and a Tamron zoom model SP 
23A (Tamron USA, Inc., Commack, NY, USA). The spectra were taken placing the glass container foreseen for the marketing of the olive paste against a white background, specifically a $\mathrm{BaSO} 4$ pressed plate (USRS-99-010, Labsphere Inc., North Sutton, $\mathrm{NH}$, USA). The entire visible spectrum $(380-770 \mathrm{~nm})$ was recorded $(\Delta \lambda=1 \mathrm{~nm})$ and the Illuminant D65 and the $10^{\circ}$ observer were considered as references.

The color parameters corresponding to the uniform color space CIELAB $\left(\mathrm{L}^{*}, \mathrm{a}^{*}, \mathrm{~b}^{*}, \mathrm{C}^{*}{ }_{\mathrm{ab}}\right.$ and $\left.\mathrm{h}_{\mathrm{ab}}\right)$ (CIE, 1986) were obtained directly from the apparatus. $L^{*}$ is an approximate measure of luminosity and its values oscillate between 0 (black) and 100 (white). The color coordinate $\mathrm{a}^{*}$ is higher than zero for reddish colors and lower than zero for greenish ones. On the other hand, $b^{*}$ takes positive values for yellowish colors and negative values for bluish ones. Additionally, two psychological parameters, namely hue (hab) and chroma $\left(\mathrm{C}_{\mathrm{ab}}{ }^{*}\right)$ are defined, which are related to $\mathrm{a}^{*}$ and $\mathrm{b}^{*}$ as follows:

$$
\mathrm{C}^{*}{ }_{\mathrm{ab}}=\left[\left(\mathrm{a}^{*}\right)^{2}+\left(\mathrm{b}^{*}\right)^{2}\right]^{1 / 2} \mathrm{~h}_{\mathrm{ab}}=\arctan \left(\mathrm{b}^{*} / \mathrm{a}^{*}\right)
$$

$\mathrm{C}^{*}{ }_{\mathrm{ab}}$ is regarded as the quantitative attribute of colorfulness and reflects the degree of difference relative to a grey color with the same lightness for each hue. Hue angle takes values from $0^{\circ}$ to $360^{\circ}$ and is the qualitative attribute that allows any color to be described as bluish, reddish, etc. This parameter allows any color to be differentiated from a grey one with the same lightness. The color differences $\left(\Delta \mathrm{E}^{*}{ }_{\mathrm{ab}}\right)$ between two colors in the CIELAB space are calculated as the Euclidean distance between their locations in the threedimensional space defined by $L^{*}, a^{*}$ and $b^{*}$ :

$$
\Delta \mathrm{E}^{*}{ }_{\mathrm{ab}}=\left[\left(\Delta \mathrm{L}^{*}\right)^{2}+\left(\Delta \mathrm{a}^{*}\right)^{2}+\left(\Delta \mathrm{b}^{*}\right)^{2}\right]^{1 / 2}
$$

\section{RESULTS AND DISCUSSION}

\subsection{Paste formulation}

The Manzanilla table olives provided by the industry were preserved in highly salted brine. In the industry, the characteristic salty taste of the final product is obtained by washing the olives until the desired salt content is obtained. Consequently, our starting point to formulate the paste was to establish the appropriate washing procedure leading to a salt content that was appealing for the consumer. In this regard, up to three different washing procedures were assayed. Thus, pastes were produced with the initial raw olives [TO0] and with the three different washing procedures, which were used for a rank order test. The sum scores (R) from all the judges were $10,20,30$ and 40 for the samples [T00], [T30], [T60] y [T90] respectively. After analyzing the results with the Friedman's test, it was concluded that there were statistically significant differences among them $(p<0.01)$ $\left(F=30>F_{\text {critical }}=11.34, \alpha=0.01\right)$ (Table 2). The pair comparison tests, computed according to the minimal significant differences of Fisher, indicated that [T00] was significantly different from [T60] and [T90] $(p=0.01)$ and that [T30] and [T90] also differed significantly $(p=0.05)$. In light of these results it was concluded that the favorite sample was the one soaked in water for 90 minutes [T90] with water changes every 30 minutes. This washing procedure was followed for the production of all the pastes hereafter.

\subsection{Texture paste selection}

In a second stage, it was necessary to determine the appropriate texture for the production of the paste. For this purpose two attributes were taken into consideration separately: texture in the mouth and visual texture. After performing a paired comparison test, $98.3 \%$ of the judges found differences among the pastes assessed. These differences proved statistically significant $(p<$ 0.0001 ) on the basis of the results of the corresponding ANOVA test.

To identify the pairs of samples that were significantly different a post hoc comparisons Tukey HSD test was applied. For this purpose it was assumed that the variances in the different groups were identical (Levene test $p>0.05$ ([F]/[M]/[L]: $p=$ 0.098; $[\mathrm{FO}] /[\mathrm{MO}] /[\mathrm{LO}]: \mathrm{p}=0.098$ ). In both groups (pastes with and without oil) significant differences $(p<0.01)$ in granularity were found for all the pairs considered.

As can be observed in Figure 2a, when the samples prepared without added oil were considered, the medium-grained texture got the best scores for mouth texture. Concerning visual texture, both the fine and medium-grained pastes were scored alike. In contrast, considering the samples prepared with added oil, the fine-grained sample was the best scored when both the visual and the mouth texture were considered (Figure 2b). The ANOVA test revealed that only the pastes produced without oil differed significantly for mouth texture $(p=0.0083)$ and visual texture $(p=$ $0.0000)$. Contrarily no significant differences were found in the samples with added oil.

To identify the pairs of samples that were significantly different in terms of mouth texture, a post hoc comparisons Tukey HSD test was applied. In this regard, it was assumed that the variances in the different groups within the design were identical, because the Levene test for $[\mathrm{F}] /[\mathrm{M}] /[\mathrm{L}]$ resulted in $\mathrm{p}$ $=0.790$ for mouth texture. In light of the outcome of the test, it was concluded that only the mediumgrained paste differed significantly $(p=0.0294)$ from the coarse paste.

When the studied attribute was the visual texture, the Games-Howell test was applied to compute the post hoc comparisons (variances were not identical, since the Levene test for $[\mathrm{F}] /[\mathrm{M}] /[\mathrm{L}]$ was $p<0.05)$. The large-grained paste differed significantly $(p=0.018)$ from the fine-grained and medium-grained pastes. 
a.

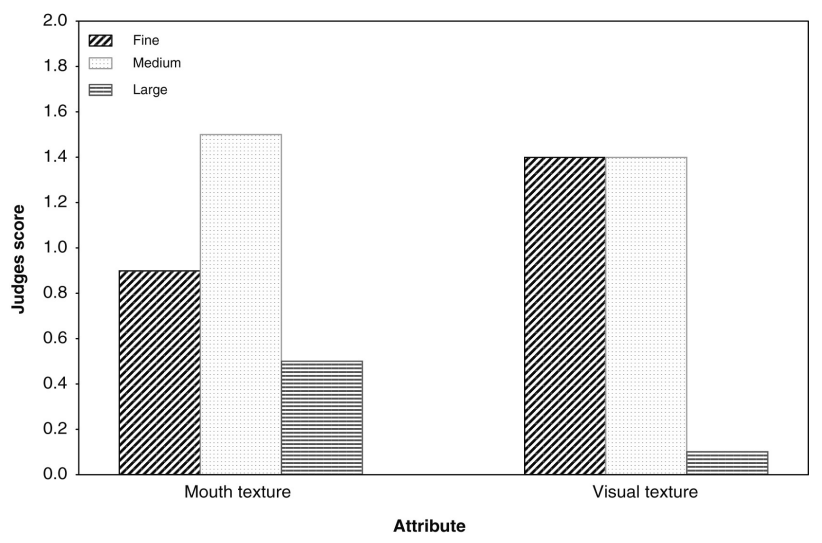

b.

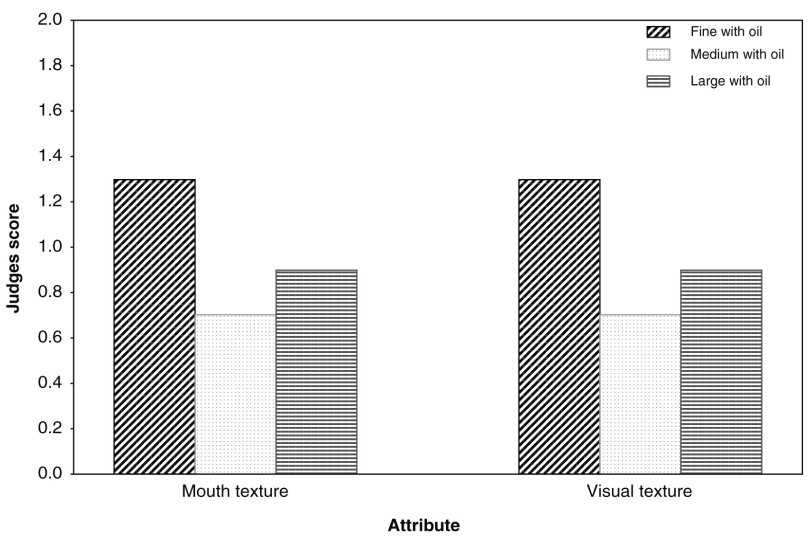

Figure 2

Summary of the judges' answers in the paired comparison tests for the selection of the paste texture. a. Preferences for the samples without oil. b. Preferences for the samples with oil

The summary of the rank-preference scores is shown in Figures $3 a$ (pastes without oil) and 3b (pastes with oil). Lower rank sum scores indicated that the samples were less appealing, while higher rank sum scores indicated the opposite. The highest-scored samples for both attributes (mouth texture and visual texture) were the samples $[\mathrm{F}]$ and [M]. Regarding the samples with oil similar results were obtained for mouth and visual texture, even though the sample [MO] was preferred in the mouth and the sample [LO] was the preferred visually (Figure 3b).

The statistical results are summarized in Table 2. The results of the Friedman's test indicated that there were significant differences only for visual texture in the three samples without oil $(F=9.6$; $\left.\mathrm{F}_{\text {critical }}=8.6, \mathrm{p}=0.01\right)$. The sample with coarse texture [L] was found significantly different $(p=$ 0.01 ) from the samples [F] and [M].

Taking together the results obtained for the different tests carried out to select the texture, the sample [L] was eventually ruled out, such that only the "medium" [M] and the "fine" [F] pastes were considered for the remaining assays.

\subsection{Selection of the amount of oil}

Virgin olive oil was an ingredient of the paste formula that had to be evaluated with special attention as it was added to the paste during elaboration and it was also used as covering oil.

In general, $50 \%$ of the judges found differences among the medium-sized pastes and $74 \%$ among the fine-sized ones. Taking into account the medium-sized pastes, the most appealing samples when the three attributes (taste, mouth and visual texture) were considered were always the ones produced with virgin olive oil and with covering oil (Figure 4a). However, the results of the ANOVA test indicated that there were not significant differences among the medium-sized pastes $([\mathrm{M}] /[\mathrm{MO}] /[\mathrm{MC}] /[\mathrm{MOC}])$ for any of the attributes considered (taste: $p=0.27$, mouth texture: $p=$ 0.09 , visual texture: $p=0.17$ )

Taking into account the fine-grained pastes, the results of the paired comparison test indicated that the "fine-grained with covering" [FC] paste was the most appealing (Figure 4b). Only in the case of the visual texture, the sample $[\mathrm{F}]$ had a similar score to that of a.

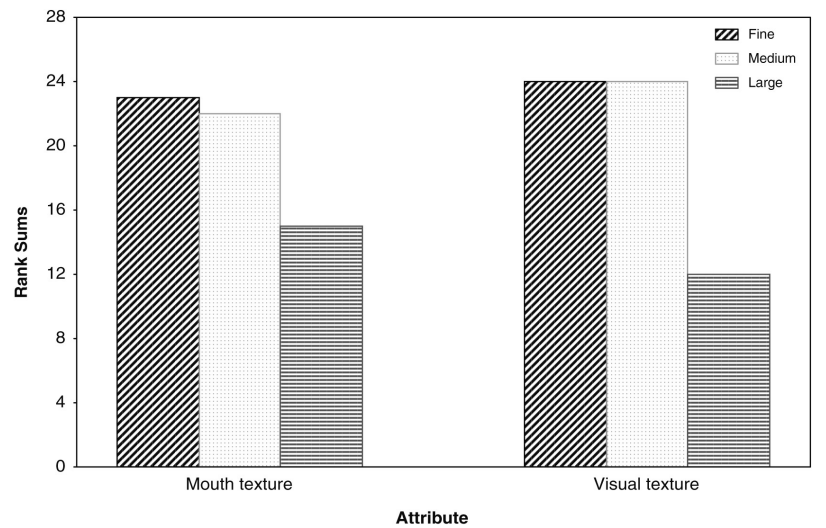

b.

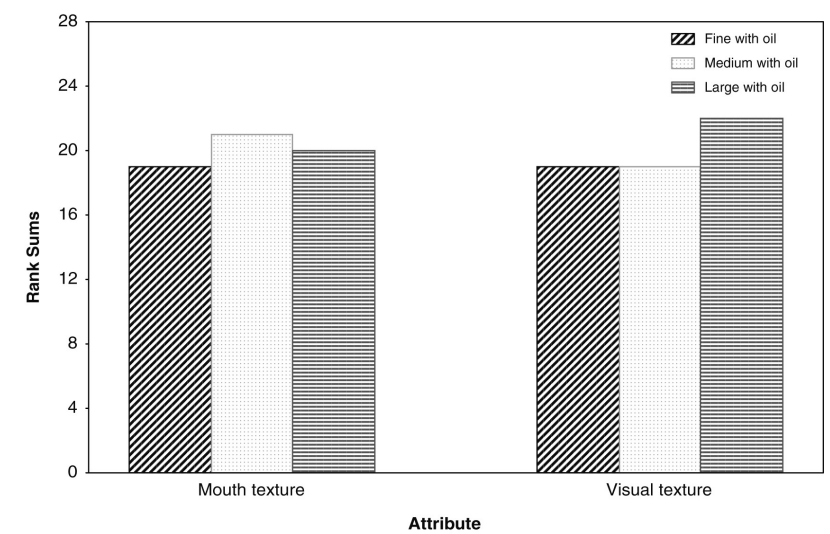

Figure 3

Summary of the judges' answers in the in the rank-order test for the selection of the paste texture.

a. Preferences for the samples without oil. b. Preferences for the samples with oil 
Table 2

Summary of the results of the Friedman's tests

\begin{tabular}{|c|c|c|c|c|c|c|}
\hline Experiment & Attribute & Samples* & $\begin{array}{c}\text { № } \\
\text { judges }\end{array}$ & $\begin{array}{c}\text { F } \\
\text { (Friedman) }\end{array}$ & $\begin{array}{c}F_{\text {critical }} \\
(\alpha=0.05)\end{array}$ & $\begin{array}{c}\mathbf{F}_{\text {critical }} \\
(\alpha=0.01)\end{array}$ \\
\hline Washing & Salt taste & 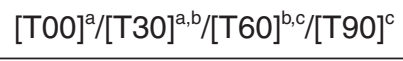 & 10 & 30 & 7.81 & 11.34 \\
\hline \multirow{2}{*}{$\begin{array}{c}\text { Texture } \\
\text { (granularity) }\end{array}$} & $\begin{array}{l}\text { Visual } \\
\text { texture }\end{array}$ & 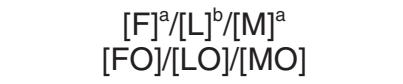 & $\begin{array}{l}10 \\
10\end{array}$ & $\begin{array}{l}9.6 \\
0.6\end{array}$ & \multirow{2}{*}{6.20} & \multirow{2}{*}{8.60} \\
\hline & $\begin{array}{l}\text { Mouth } \\
\text { texture }\end{array}$ & $\begin{array}{c}{[\mathrm{F}] /[\mathrm{L}] /[\mathrm{M}]} \\
{[\mathrm{FO}] /[\mathrm{LO}] /[\mathrm{MO}]}\end{array}$ & $\begin{array}{l}10 \\
10\end{array}$ & $\begin{array}{l}3.6 \\
0.2\end{array}$ & & \\
\hline \multirow{3}{*}{$\begin{array}{l}\text { Quantity } \\
\text { of added oil }\end{array}$} & $\begin{array}{l}\text { Visual } \\
\text { texture }\end{array}$ & $\begin{array}{c}{[\mathrm{M}]^{\mathrm{a} /} /[\mathrm{MO}]^{\mathrm{b}, \mathrm{c}} /[\mathrm{MC}]^{\mathrm{a}, \mathrm{c}} /[\mathrm{MOC}]^{\mathrm{b}}} \\
{[\mathrm{F}] /[\mathrm{FO}] /[\mathrm{FC}] /[\mathrm{FOC}]}\end{array}$ & $\begin{array}{l}8 \\
9\end{array}$ & $\begin{array}{l}9.2 \\
2.2\end{array}$ & 7.65 & 10.35 \\
\hline & $\begin{array}{l}\text { Mouth } \\
\text { texture }\end{array}$ & $\begin{array}{c}{[\mathrm{M}] /[\mathrm{MO}] /[\mathrm{MC}] /[\mathrm{MOC}]} \\
{[\mathrm{F}] /[\mathrm{FO}] /[\mathrm{FC}] /[\mathrm{FOC}]}\end{array}$ & $\begin{array}{l}9 \\
9\end{array}$ & $\begin{array}{l}7.5 \\
4.5\end{array}$ & \multirow[t]{2}{*}{7.81} & \multirow[t]{2}{*}{11.34} \\
\hline & Taste & $\begin{array}{c}{[\mathrm{M}] /[\mathrm{MO}] /[\mathrm{MC}] /[\mathrm{MOC}]} \\
{[\mathrm{F}] /[\mathrm{FO}] /[\mathrm{FC}] /[\mathrm{FOC}]}\end{array}$ & $\begin{array}{c}10 \\
9\end{array}$ & $\begin{array}{l}3.7 \\
3.4\end{array}$ & & \\
\hline Consumers & $\begin{array}{c}\text { Overall } \\
\text { preference }\end{array}$ & {$[\mathrm{MC}] /[\mathrm{MOC}] /[\mathrm{FC}]$} & 40 & 1.3 & 5.99 & 9.21 \\
\hline Pasteurization & $\begin{array}{c}\text { Overall } \\
\text { preference }\end{array}$ & 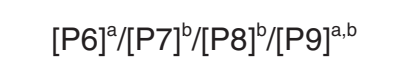 & 9 & 6.7 & 7.81 & 11.34 \\
\hline
\end{tabular}

${ }^{*}$ Different superscripts in the same row indicate significant differences $(p<0.05)$.

the sample $[F C]$. However, there were not significant differences $(p<0.05)$ among the fine-grained pastes $([\mathrm{F}] /[\mathrm{FO}] /[\mathrm{FC}] /[\mathrm{FOC}])$ (taste: $\mathrm{p}=0.14$, mouth texture: $p=0.69$, visual texture: $p=0.32)$.

The results of the rank-preference test for the two textures assayed are summarized in Figure 5, the lower rank sum score indicating the lowest preference. Considering taste and mouth texture the best-scored sample in the medium-grained pastes was the one containing covering oil (Figure $5 a)$. Contrastingly the one without oil was preferred when the visual texture was evaluated.

Regarding the fine-sized pastes, the favorite samples were the "fine with covering oil" [FC] one when the mouth and visual texture were evaluated. When the taste was assessed the results obtained were similar for FO and FOC.

The Friedman's test applied to the preference ranking tests, revealed that the samples [M], [MO],

a.

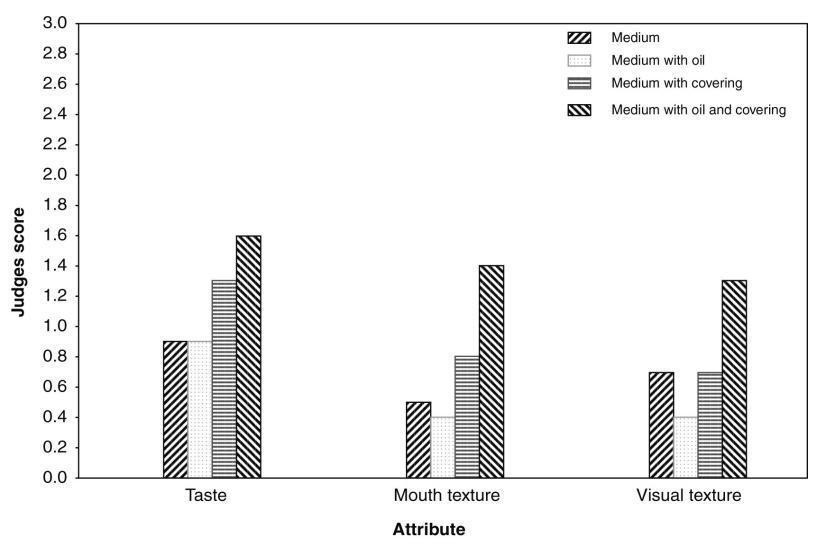

Figure 4

Summary of the judges' answers in the paired comparison tests for the selection of the oil content. a. Preferences for the medium-grained samples. b. Preferences for the fine-grained samples
$[\mathrm{MC}]$ and $[\mathrm{MOC}]$ were significantly different in terms of visual texture $\left(F=9.2 ; F_{\text {critical }}=7.7, p<0.05\right)$ (Table 2). [M] was significantly different $(p<0.05)$ to both $[\mathrm{MO}]$ and $[\mathrm{MOC}]$, and $[\mathrm{MC}]$ was significantly different $(p<0.05)$ to [MOC].

In order to select the final formulations of pastes to be evaluated by the consumer panel, the results of the different tests were taken into account. The final selection included the best scored pastes, that is, [MC], [MOC] and [FC].

\subsection{Formula selection and preservation conditions}

A consumer panel of 40 judges evaluated the selected pastes by means of a rank preference test. The rank sum scores $(R)$ from all the panellists were 75, 80 and 85 for the samples [MC], [MOC] and $[F C]$, respectively, the last being therefore the

b.

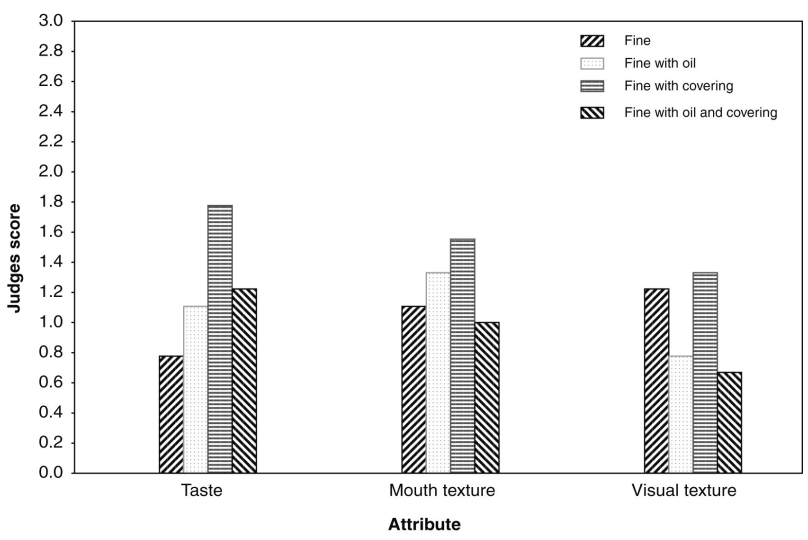


a.

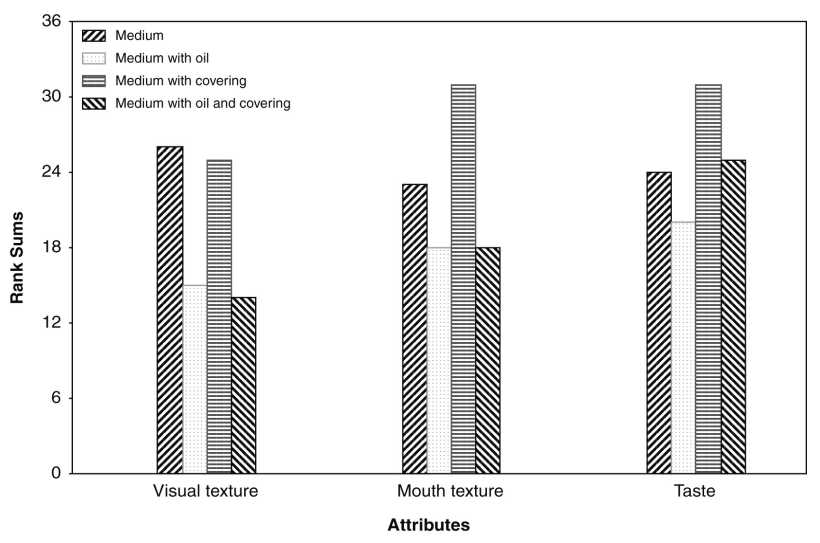

b.

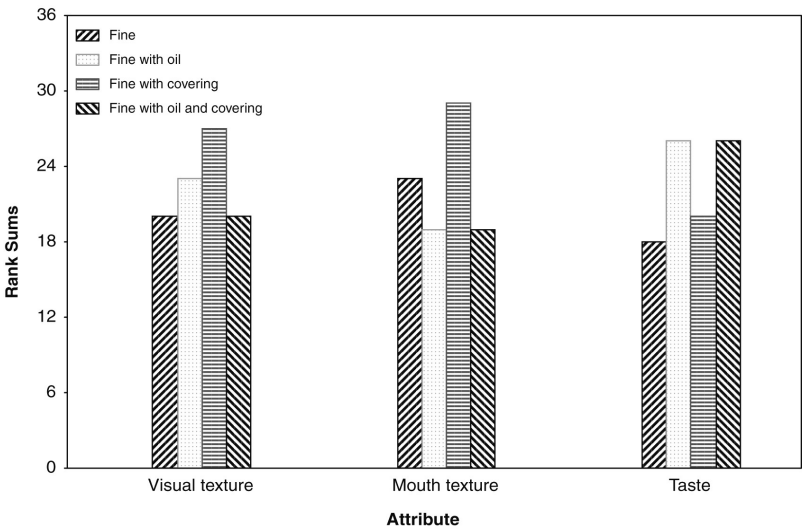

Figure 5

Summary of the judges' answers in the rank-order tests for the selection of the oil content.

a. Preferences for the medium-grained samples. b. Preferences for the fine-grained samples

favorite. However, after applying the Friedman's test, it was found that $[\mathrm{MC}],[\mathrm{MOC}]$ and $[\mathrm{FC}]$ were not significantly different $(\mathrm{p}<0.05)(\mathrm{F}=1.25<$ $\mathrm{F}_{\text {critical }}=5.99$, for 40 judges at $\left.\alpha=0.05\right)$.

The highest scored paste ([FC]) was submitted to different pasteurization conditions, after which its color was objectively measured by Tristimulus Colorimetry as this sensory attribute can be affected by heating. The location of the samples within the $\left(a^{*} b^{*}\right)$ plane as a function of the pasteurization conditions assayed is shown in Figure 6. All the samples are clustered in the brownyellow area of the diagram, with values of $a^{*}$ and $b^{*}$ around 2 and 27 CIELAB units, respectively. The values of chroma $\left(\mathrm{C}^{*}{ }_{\mathrm{ab}}\right)$, hue $\left(\mathrm{h}_{\mathrm{ab}}\right)$ and lightness $\left(\mathrm{L}^{*}\right)$ obtained as a function of the different pasteurization temperatures assayed varied only slightly (Table 3 ). In view of these objective instrumental data, we concluded that the thermal treatments tested did

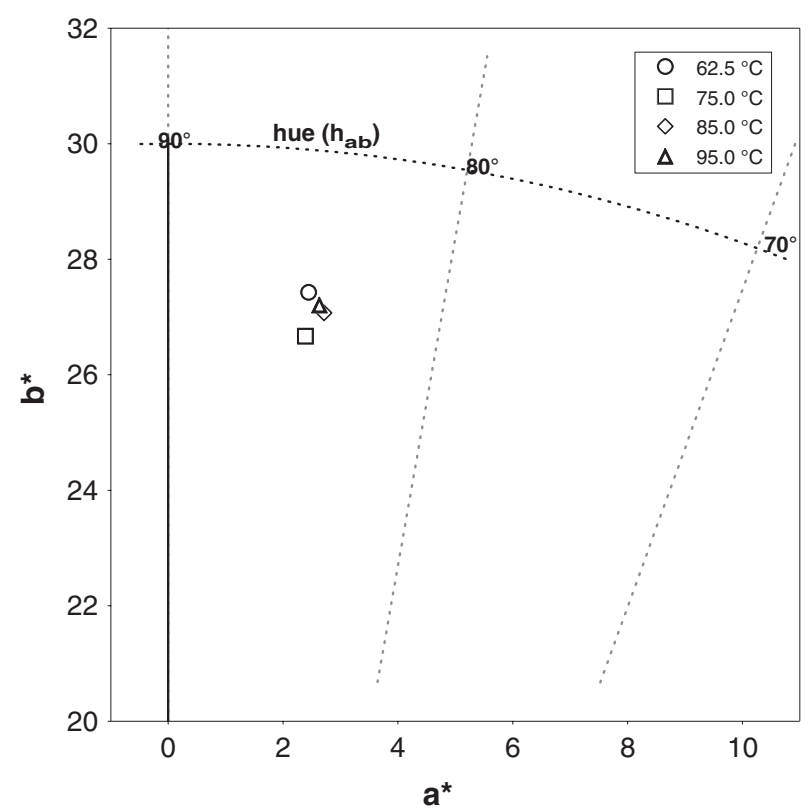

Figure 6

Location of the samples subjected to thermal treatments within the $\left(a^{*} b^{*}\right)$ plane.
Table 3

Values of the color coordinates $C^{\star} a b$, hab and $L^{*}$ as a function of the pasteurization temperatures assayed

\begin{tabular}{cccc}
\hline $\begin{array}{c}\text { Pasteurization } \\
\text { temperature }\end{array}$ & $\mathbf{L}^{*}$ & $\mathbf{h}_{\mathrm{ab}}$ & $\mathbf{C}^{*}{ }_{\mathrm{ab}}$ \\
\hline $62.5^{\circ} \mathrm{C}$ & 60.415 & 84.903 & 27.534 \\
$75^{\circ} \mathrm{C}$ & 56.540 & 84.873 & 26.667 \\
$85^{\circ} \mathrm{C}$ & 57.757 & 84.272 & 27.205 \\
$95^{\circ} \mathrm{C}$ & 60.384 & 84.465 & 27.333 \\
\hline
\end{tabular}

not lead to marked changes in the color of the pastes. These results are in agreement with those reported by Sánchez et al. (1991) for pickled green olives.

At any rate, considering the goal of the study, it was far more important to ascertain whether the pasteurization conditions tested led to color changes visually discernible by consumers. The rank sum scores $(R)$ obtained for the thermally treated pastes were 14, 25, 27 and 24, for the samples [P6], [P7], [P8] and [P9], respectively. It was clearly seen that the highest scored sample was the one pasteurizated at $85{ }^{\circ} \mathrm{C}$ and that the sample heated at $62.5^{\circ} \mathrm{C}$ was by far the least appealing. According to the Friedman's test the samples were not significantly different $(F=6.73<$ $\left.\mathrm{F}_{\text {critical }}=7.8\right)$. However, when pairs of samples were considered significant $(p<0.05)$ differences were found between [P6] and [P7] and [P8] (Table 2). In view of these results, $85^{\circ} \mathrm{C}$ was selected as the most appropriate pasteurization temperature.

\section{CONCLUSIONS}

The main objective of this study was to develop an optimized and experimental protocol based on sensory evaluation to select a final formulation of an olive-fruit based product. The selected paste formulation was characterized by a fine grain texture without added olive oil in the whipping stage 
but covered with olive oil. According to the sensory panels this paste was preferred due its moist but not greasy texture and its delicate and smooth taste.

\section{ACKNOWLEDGMENTS}

This research was supported by the Spanish food industry Aceites del Sur S.A. with the project $2003 / 980$

\section{REFERENCES}

Abdullah A, Cheng TG. 2001. Optimization of reduced calorie tropical mixed fruits jam. Food Qual Prefer 12, 63-68.

Abu-Salem FM, Abou-Arab, AA. 2008. Evaluación química, microbiológica y sensorial de mayonesa preparada con huevos de avestruz. Grasas Aceites 59, 352-360.

Calvo C, Salvador A, Fiszman SM. 2001. Influence of color intensity on the perception of color and sweetness in various fruitflavoured yoghurts. Eur. Food Res. Technol. 213, 99-103.

CIE. 1986. Colorimetry (2nd ed.; Publication 15.2). Bureau Central de la CIE, Viena.

Coello MT, Sánchez MJ, Vicario IM, Heredia FJ, Martín M. 1999. Assessing acceptability of eel (Anguilla anguilla) fed three different diets. J. Sci. Food Agr. 79 (15), 2087-2093.

Coleman CJ. 1990. Applications of qualitative research for sensory analisis and product development. Food Technol. 44 (11), 164-174.

Deshpande RP, Chinnan MS, McWatters KH. 2008. Optimization of a chocolate-flavored, peanut-soy beverage using response surface methodology (RSM) as applied to consumer acceptability data. LWT - Food Sci. Technol 41 (8), 1485-1492.

Fisher L. 1998. Rattlesnake bites-treatment or mistreatment?. Nurs. Spectrum 8, 20-23.

Friedman M. 1937. The use of ranks to avoid the assumptions of normality implicit in the analysis of variance. J. Amer. Statist. Assoc. 32, 675-701.

González F, Rejano L, González F. 1982. La pasterización de aceitunas estilo sevillano, I. Grasas Aceites 33, 201-207.

González MM, Navarro T, Gómez G, Pérez RA, de Lorenzo C. 2007. Análisis sensorial de aceituna de mesa: II. Aplicabilidad práctica y correlación con el análisis instrumental. Grasas Aceites 58, 231-236.

Hollander M, Wolfe DA. 1973. Nonparametric Statistical Methods (p. 151). Wiley, New York.
Hutchings JB. 1994. Food color and appearance. Blackie Academic \& Professional, Glasgow.

IOOC. 2004. Trade Standard Applying to Table Olives, (Res-2/91-IV/04). International Olive Oil Council, Madrid.

ISO 5495. 1983. Sensory Analysis. Methodology. Paired comparision test. International Organization for Standardization, Genève, Switzerland.

ISO 8587. 2001. Sensory Analysis. Methodology-Ranking. International Organization for Standardization, Genève, Switzerland.

Lawless HT, Michelle RC. (1993). Application of the central dogma in sensory evaluation. Food Technol. 47 (6), 139-146.

Moldão-Martins $M$, Berião-da-Costa $S$, Neves C, Cavaleiro C, Salgueiro L, Berião-da-Costa ML. 2004. Olive oil flavoured by the essantial oils of Mentha $x$ piperita and Thymus mastichina L. Food Qual. Prefer. 15, 447-452.

Moskowitz H, Gofman A, Beckley J. 2005. Using high-level consumer-research methods to create a tool-driven guidebook and database for product development and marketing. J. Sens. Stud. 21, 54-100.

Muñoz AM, Civille GV, Carr BT. 1992. Sensory evaluation in quality control. Van Nostrand Reinhold, New York.

Norman GR, Streiner DL. 1996. Bioestadística. Mosby/ Doyma Libros, S.A. Times Mirror International Publishers, Madrid.

Pecore S, Kellen L. 2002. A consumer-focused QC/sensory program in the food industry. Food Qual. Prefer. 13, 369-374.

Royer G, Madieta E, Symoneaux R, Jourjon F. 2006. Preliminary study of the production of apple pomace and quince jelly. LWT - Food Sci. Technol. 39, 10221025.

Sánchez Gómez AH, García García P, Rejano Navarro L. 2006. Trends in table olive production. Grasas Aceites 57 (1), 86-94.

Sánchez AH, Rejano L, Montaño A. 1991. Kinetics of the destruction by heat of color and texture of pickled green olives. J. Sci. Food Agr. 54, 379-385.

Sozer N, Dalgiç A, Kaya A. 2007. Thermal, textural, and cooking properties of spaghetti enriched with resistant starch. J. Food Eng. 81, 476-484.

StatSoft Inc. 2001. Data analysis software system (Statistica for Windows v.6.0). Tulsa, Oklahoma.

Yantis JE. 1992. Introduction/program objectives for plant sensory function in QA/QC programs, in Yantis JE (Ed.) The role of sensory analysis in quality control (ASTM Manual Series: MNL 14, pp. 1). American Society for Testing and Materials, Philadelphia, pp.1.

Recibido: 21/1/09 Aceptado: 9/3/09 